\title{
Periodontal Surveillance - Implications in the Promotion of Public Health
}

\author{
William V. Giannobile*
}

$\mathrm{T}$ This month, the Journal of Periodontology is very pleased to provide our readers a special supplement on periodontal disease surveillance. Disease surveillance has been crucial in the identification and tracking of susceptible patient populations to infectious agents. The Centers for Disease Control and Prevention (CDC) works to protect public health and the safety of people, by providing information to enhance health decisions, and promotes health through partnerships with state health departments and other organizations. Thus, the CDC has benefitted the periodontal community through a special supplement borne out of the recent CDC and American Academy of Periodontology (CDC-AAP) Workshop on Periodontal Surveillance. In this main issue of the Journal, you will find an editorial and commentary that highlight the relevance of this topic to public health and the advancement of periodontal case definitions in the clinical and field trial settings. First, an editorial by Drs. William Maas and Robert Genco titled "CDC Periodontal Disease Surveillance Project Could Help States Plug Data Gaps"1 is presented. In this editorial, the authors underscore the importance of self-report measures for populationbased surveillance programs in the United States. The partnership with the CDC served as an important collaborative effort with other clinical researchers in the development of the guidelines found in the corre- sponding supplement. A commentary by Dr. Jasim Albandar discusses the advantages and limitations that public health clinical researchers face in the case definitions for periodontal disease risk assessment. ${ }^{2}$

The editors of the Journal along with the Guest Editor for this supplement, Dr. Paul Eke, trust that you will find that research in this area will greatly promote the advancement of periodontal disease surveillance. ${ }^{3}$ It is this work that can aid periodontists in the better understanding of periodontitis disease patterns in broad patient populations beyond our clinics and schools for the ultimate promotion of enhanced public health.

\section{REFERENCES}

1. Maas W, Genco RJ. CDC Periodontal Disease Surveillance Project could help states plug data gaps. $J$ Periodontol 2007;78:1178.

2. Albandar JM. Periodontal disease surveillance. J Periodontol 2007;78:1179-1181.

3. Eke PI, Genco RJ. CDC Periodontal Disease Surveillance Project: Background, objectives, and progress report. J Periodontol 2007;78(Suppl.):1366-1371.

Correspondence: Dr. William V. Giannobile, Michigan Center for Oral Health Research, University of Michigan Clinical Center, 24 Frank Lloyd Wright Dr., Lobby M, Box 422, Ann Arbor, MI 48106. Fax: 734/998-7228; e-mail: wgiannob@umich.edu.
* Michigan Center for Oral Health Research and Department of Periodontics and Oral Medicine, School of Dentistry, University of Michigan, Ann Arbor, MI; Department of Biomedical Engineering, College of Engineering, University of Michigan. doi: 10.1902/jop.2007.077001 